\title{
Les francs-maçons et la laïcisation de l'école. Mythe et réalités
}

The Freemasons and the Laicization of School. Myth and Realities

Freimaurer und Entkonfessionalisierung der Schule. Mythos und Wirklichkeit

Los masones y la laicización de la escuela. Mitos y realidades

Jean-Paul Delahaye

\section{(2) OpenEdition}

Journals

Édition électronique

URL : https://journals.openedition.org/histoire-education/1328

DOI : 10.4000/histoire-education. 1328

ISSN : 2102-5452

Éditeur

ENS Éditions

\section{Édition imprimée}

Date de publication : 1 janvier 2006

Pagination : 33-73

ISBN : 2-7342-1043-6

ISSN : 0221-6280

\section{Référence électronique}

Jean-Paul Delahaye, "Les francs-maçons et la laïcisation de l'école. Mythe et réalités », Histoire de l'éducation [En ligne], 109 | 2006, mis en ligne le 01 janvier 2011, consulté le 20 mai 2021. URL : http:// journals.openedition.org/histoire-education/1328; DOI : https://doi.org/10.4000/histoire-education. 1328 


\section{LES FRANCS-MAÇONS ET LA LAÏCISATION DE L'ÉCOLE}

\section{Mythe et réalités}

Par Jean-Paul DELAHAYE

Dès le début de la Troisième République, les adversaires des francs-maçons, et particulièrement le clergé catholique et les monarchistes, ont très violemment attaqué la franc-maçonnerie en lui prêtant une influence essentielle dans l'instauration de la laïcité à l'école primaire: «Pour attaquer les catholiques, pour déchristianiser la France, Jules Ferry devait s'appuyer sur trois forces hostiles aux catholiques: les juifs, les libres penseurs et surtout les francsmaçons; et les juifs, les libres penseurs et les francs-maçons ont domestiqué la République» (1). Cette attitude d'une certaine Église soucieuse de défendre ses positions établies dans l'enseignement, correspond-elle à la réalité, ou bien est-elle une justification commode trouvée par les cléricaux pour expliquer une évolution qui ne serait, au bout du compte, que le résultat «tout au long du siècle [...] d'une évolution sociale profonde?»(2). Sur l'instant, les francsmaçons eux-mêmes n'ont démenti ces accusations que bien mollement et ont, par la suite, donné largement du crédit à une accusation qui les valorisait.

Quel a été, dans la réalité, le rôle des loges et des organes dirigeants de la franc-maçonnerie dans la préparation de la loi de 1882 ? Nous nous proposons de répondre à cette question, d'une part en rendant compte de la manière dont les francs-maçons ont abordé la laïcité dans les discussions organisées dans les loges et dans la presse maçonnique avant 1879 et, d'autre part, en observant l'attitude des

(1) Souvenirs du député royaliste Arthur Meyer, cités par Pierre Chevallier: La séparation de l'Église et de l'École. Jules Ferry et Léon XIII, Paris, Fayard, 1981, p. 172.

(2) Antoine Prost: Histoire de l'enseignement en France 1800-1967, Paris, Armand Colin, 1968, p. 191. 
parlementaires francs-maçons lors de la discussion au Sénat et à la Chambre des députés de la loi de 1880-1882 sur la scolarité obligatoire et la laïcité.

\section{UNE OBÉDIENCE MULTIFORME ET EN MOUVEMENT}

La franc-maçonnerie de l'époque est essentiellement représentée par les loges du Grand Orient de France. À la fin du Second Empire et au début de la Troisième République, le Grand Orient de France a connu de profonds bouleversements. Ses effectifs ont cru de façon importante, puisque l'Obédience passe de 8500 membres au milieu du Second Empire à 18000 membres dans les années 1880. C'est pendant cette période que l'Ordre s'est laïcisé, une première fois mais timidement en 1865, puis définitivement en 1877 (1).

La plupart des loges sont fréquentées par les représentants de la petite et moyenne bourgeoisie. Les commerçants, les négociants, les marchands de vin, les petits propriétaires ou rentiers, les artisans, les employés, forment l'essentiel des recrues de cette période. On trouve aussi une minorité agissante et de plus en plus influente de médecins, d'avocats, de journalistes, d'ingénieurs, de pharmaciens, d'architectes, d'hommes d'affaires et de fonctionnaires, qui composent progressivement les cadres dirigeants de l'Ordre. Au total, aux côtés de notables et de petits artisans (les milieux populaires sont davantage représentés dans les loges parisiennes qu'en province), les loges accueillent en nombre croissant ceux que Gambetta a appelés, dans son discours de Grenoble de 1872, les «couches nouvelles.»

Contrairement à une idée reçue, on ne trouve pratiquement pas d'enseignants dans les loges à l'époque. Il est extrêmement rare, en effet, de voir figurer des instituteurs dans les listes de francs-maçons. Citons par exemple le cas de la loge parisienne qui initie Jules Ferry en 1875, La Clémente Amitié, qui compte 115 membres en 1869 mais seulement deux instituteurs (2). La présence plus importante des

(1) Pour plus de détails, voir notre thèse Les francs-maçons et l'instruction publique de 1861 à 1882, Université René Descartes-Paris 5, 2003. Voir aussi André Combes: Histoire de la franc-maçonnerie au XIXe siècle, Paris, Éditions du Rocher, 2 tomes, 1998 et Pierre Chevallier: Histoire de la franc-maçonnerie française, Paris, Fayard, 3 tomes, 1975.

(2) Ces deux instituteurs ont d'ailleurs des responsabilités au sein de la loge puisque l'un est Deuxième Surveillant et l'autre Grand Expert. Archives de la loge, Bibliothèque du Grand Orient de France. 
enseignants est pourtant souhaitée, si l'on en croit les vœux émis, sans succès d'ailleurs, par certaines loges à l'occasion des Convents (1) pour que l'on consente un tarif réduit aux instituteurs pour le paiement de la capitation (2), trop chère pour eux. On peut citer un vœu significatif émis en 1869 par plusieurs loges de Valence, de Marseille et d'Aubenas et repoussé par le Convent de 1870: «Considérant qu'il importe de faciliter la propagande des principes maçonniques parmi ceux qui sont chargés de l'instruction de l'enfance, les soussignés émettent le vœu qu'il soit permis aux loges de l'Obédience d'initier les instituteurs ruraux à prix réduit» (3).

On doit relever cependant que les loges recrutent une partie de leurs adhérents dans le milieu des petits artisans, c'est-à-dire dans une partie de la population qui devait également éprouver des difficultés financières. Le coût de la capitation n'est donc pas la seule raison qui explique l'absence des instituteurs. Très dépendants des autorités locales que sont les maires, les ecclésiastiques ou les préfets, les enseignants ont été également rendus prudents par des événements récents, comme la destitution de centaines d'instituteurs après la révolution de 1848 . Ils ne se rapprocheront de la franc-maçonnerie qu'au moment de l'installation définitive de la République, après 1880, et ne participeront donc pas aux premiers débats sur la laïcité au sein des loges.

Quant aux hommes politiques, ils intéressent évidemment beaucoup les francs-maçons car ils voient en eux des relais en mesure de faire progresser leurs idées. À partir de 1861, l'attitude relativement bienveillante de l'Empire libéral et la montée de l'anticléricalisme permettent aux loges d'attirer à elles des élus, notamment des opposants au régime, qui joueront un rôle déterminant par la suite. Une figure exemplaire est celle d'Eugène Pelletan (4), protestant et

(1) Un Convent est l'assemblée générale annuelle de toutes les loges de l'Ordre.

(2) La capitation est la cotisation payée annuellement par les francs-maçons à leur loge, qui en reverse elle-même une partie au Grand Orient. Le coût de l'admission est d'environ 100 francs. Il faut y ajouter une contribution annuelle de vingt à trente francs. Cela représente en effet un montant dissuasif pour un instituteur.

(3) Bulletin du Grand Orient de France, que nous appellerons à présent $B D G O D F$, juillet 1869, p. 362.

(4) Une récente étude est très utile pour connaître l'itinéraire d'Eugène Pelletan, voir Paul Baquiast: Une dynastie de la bourgeoisie républicaine: les Pelletan, Paris, L'Harmatan, 1996. 
républicain. Parmi les hommes politiques qui entrent dans la francmaçonnerie sous le Second Empire, on peut encore citer Léon Gambetta, initié à Marseille en mai 1869, et Jules Simon, initié le 3 juillet 1870 à Boulogne-sur-Seine, dans la loge Le Réveil maçonnique.

Les loges maçonniques du Second Empire sont donc globalement représentatives d'une bourgeoisie éclairée, connaissant l'importance d'une instruction solide. Beaucoup, parmi les nouveaux initiés, doivent à l'école leur ascension sociale. Encore déistes dans leur majorité, mais fondamentalement anticléricales, les loges sont progressivement investies par des libres penseurs athées.

La laïcisation du Grand Orient de France, en 1877, est très largement l'aboutissement de l'influence exercée par ces nouveaux membres, adeptes du rationalisme philosophique et du positivisme. Ces nouveaux initiés libres penseurs sont des francs-maçons d'un nouveau style qui vont bouleverser un rapport de forces établi jusqu'alors en faveur des seuls spiritualistes. De façon générale, les francsmaçons cultivés et en mesure de faire avancer la réflexion sont assez peu nombreux dans les loges. Quand nous évoquerons les idées débattues dans les ateliers maçonniques, nous parlerons donc de la réflexion conduite par une minorité d'intellectuels. Ces francsmaçons s'inspirent des Lumières et ont lu Condorcet. Ils lisent les traductions récentes de Kant et vulgarisent, en s'appuyant sur Barni et Renouvier, le néo-kantisme.

La pensée maçonnique peut donc évoluer dans le temps au gré de ses recrutements successifs. D'autre part, il peut y avoir un décalage entre le discours des dirigeants et celui des loges. La francmaçonnerie est en fait une institution "plastique, dotée d'une réelle souplesse et d'une impressionnante capacité d'adaptation aux circonstances», qui «varie dans le temps ainsi que dans l'espace» (1). Par ailleurs, il peut exister de grandes différences d'orientation idéologique entre francs-maçons et entre loges selon l'origine géographique, notamment entre les loges parisiennes nettement républicaines et certaines loges de province aux options moins définies. À la diversité philosophique et politique signalée précédemment, il faut donc ajouter cette distorsion spatiale.

(1) Sudhir Hazareesingh, Vincent Wright: Francs-maçons sous le Second Empire, Rennes, Presses universitaires de Rennes, 2001, pp. 16-17. 
En fait, il n'existe pas de pensée maçonnique homogène, pas plus qu'il n'existe d'ailleurs de pensée républicaine homogène sous le Second Empire et au début de la Troisième République, comme l'ont montré Antoine Prost, Claude Nicolet ou Mona Ozouf. Pour cette raison, et au-delà d'une unité forgée contre le cléricalisme et contre le risque de retour des révolutions, l'accord entre francs-maçons est donc difficile à réaliser au moment où s'effectuent des choix majeurs, sur la laïcité tout particulièrement. Cette très grande diversité fait d'ailleurs dire à Georges Wyrouboff, franc-maçon mais aussi philosophe positiviste proche de Littré, lors de la clôture du Convent de 1876: «La Maçonnerie ne doit pas avoir de philosophie parce qu'elle doit être unie, et qu'aucune philosophie ne rallierait à l'heure qu'il est l'unanimité des suffrages...» (1).

La période qui précède immédiatement le vote des lois scolaires est celle qui voit la disparition de la référence à Dieu dans les statuts du Grand Orient de France. Signe d'un changement du rapport des forces sur ce sujet, un premier succès est venu en 1865, avec l'introduction dans les statuts de la possibilité d'initier des non-croyants. Mais la Constitution du Grand Orient était toujours placée sous les auspices du «Grand Architecte de l'Univers» (2) et comportait, dans son article $1^{\text {er }}$, la reconnaissance de «l'existence de Dieu et l'immortalité de l'âme».

À deux reprises, en 1867 et 1875, les libres penseurs qui entrent nombreux dans les loges à ce moment avaient tenté de faire supprimer l'invocation au G.A.D.L.U. Eugène Pelletan pourra d'ailleurs déclarer au Convent de 1867 que cette question «est la seule qui divise» la franc-maçonnerie (3). Le travail de sape effectué par les libres penseurs, au premier rang desquels on trouve Alexandre Massol et un ancien pasteur protestant, Frédéric Desmons (4), aboutira au Convent de 1877. L'Assemblée générale du Grand Orient décide de l'abandon de la référence au «Grand Architecte de l'Univers ». Les loges représentées au Convent considèrent alors, à 135 contre 76, que «la franc-maçonnerie n'est pas une religion; qu'elle n'a point par conséquent à affirmer dans sa Constitution des

(1) Le Monde maçonnique, août-septembre 1876, p. 263.

(2) Les francs-maçons disent le «G.A.D.L.U.».

(3) $B D G O D F$, juin-août 1867, p. 210.

(4) Voir Daniel Ligou: Frédéric Desmons et la franc-maçonnerie sous la III République, Paris, Gedalge, 1966. 
doctrines ou des dogmes» (1). Il faut néanmoins prêter attention au fait que plus de $35 \%$ des loges s'opposent à la mutation, ce qui représente encore, au moment où les républicains sont à la veille de prendre le pouvoir, une forte minorité spiritualiste au sein de l'Obédience.

\section{LA QUESTION LAÏQUE DIVISE LES FRANCS-MAÇONS}

\section{Une lutte d'influence entre libres penseurs spiritualistes et libres penseurs athées}

Ce que les sources montrent, c'est que le débat est vif au sein des loges et des instances dirigeantes de la franc-maçonnerie sur la place de Dieu dans la vie des hommes, et tout particulièrement dans l'instruction des enfants. Il n'est pas question d'entrer ici dans le détail des discussions maçonniques sur le sujet, mais uniquement de relever les évolutions qui ont déterminé les prises de positions en matière scolaire.

La lecture des journaux maçonniques est, de ce point de vue, très éclairante. Si l'on suit, par exemple, Le Journal des initiés dirigé par un spiritualiste, Riche-Gardon (2), on voit que certains francs-maçons eux-mêmes distinguent parmi les adhérents des loges «des positivistes absolus» (3) ou athées, des «déistes» et des «théistes». Le théisme, selon Riche-Gardon, «se distingue d'un certain déisme en ce qu'il explique Dieu par la science», et non par le surnaturel. Le journal utilise d'ailleurs aussi la formule de «théisme rationaliste» pour désigner la philosophie qui a sa préférence. Adeptes d'une religion naturelle, de l'idée de progrès et convaincus du pouvoir de la science, ces francs-maçons dits théistes partagent avec les déistes (la majorité des intellectuels francs-maçons est encore déiste) le refus des dogmes qu'ils estiment relever de la superstition. En cela, ils s'opposent à la religion catholique et sont anticléricaux.

À ce premier clivage, plutôt ténu, entre spiritualistes théistes et déistes, s'ajoute une séparation évidemment plus radicale entre

(1) Cité par D. Ligou, ibid., p. 92.

(2) Sur Riche-Gardon, voir en particulier André Combes: «Charles Fauvety et la religion laïque», in Jean-Marie Mayeur (dir.): Libre-pensée et religion laïque en France, Strasbourg, Cerdic Publications, 1980, p. 31.

(3) Le Journal des initiés, mai 1863, pp. 352 - 354. 
croyants et athées. Le Journal des initiés est en effet représentatif d'une partie, encore majoritaire vers 1865 , des francs-maçons qui n'imaginent pas un instant qu'on puisse être franc-maçon et athée. La place des francs-maçons, dit Riche-Gardon, «est acquise entre les surnaturalistes et les positivistes absolus ». Les francs-maçons spiritualistes vont défendre pied à pied l'idée d'une maçonnerie spiritualiste et seront, par conséquent, opposés à une école publique ne faisant plus référence à Dieu. Les hésitations de Jean Macé, spiritualiste lui aussi (1), quand il s'est agi de dire si la Ligue de l'enseignement rejoindrait les partisans de l'école laïque, peuvent en grande partie s'expliquer de cette façon, nous y reviendrons. Même s'ils sont anticléricaux, il parait impossible aux spiritualistes d'imaginer une éducation qui ne s'appuierait pas sur une philosophie religieuse. Ils s'opposent, par exemple, à toute tentative d'introduction à l'école d'une morale qui ne serait pas fondée sur les principes de la religion naturelle, parce que cette morale serait, alors, «une morale indépendante», et donc une morale inconcevable. Ils pressentent que «la morale indépendante sera désormais la grande morale» (2), tout en continuant à penser que «la seule morale, c'est la morale universelle» (3).

\section{Un point d'accord : l'instruction publique doit échapper aux congrégations}

Les francs-maçons du début des années 1860 sont donc actifs dans le combat contre le «cléricalisme scolaire» (4) et contre ce qu'ils appellent: «les ténèbres et l'oppression [...] Nous n'admettons pas les systèmes qui réduisent l'ambition de l'homme à être simple d'esprit et contempteur des biens que la Providence a mis à notre disposition en ce monde. La civilisation, selon nos principes, est le développement de l'instruction» (5). On va voir à l'œuvre, sur ce sujet, le réseau des loges. En effet, les ateliers maçonniques vont, dès lors, multiplier les attaques contre «les Congrégations religieuses qui

(1) Voir la thèse de Jean-Paul Martin: La Ligue de l'enseignement et la République, des origines à 1914, I.E.P. de Paris, 1992.

(2) Le Journal des initiés, juillet-août 1865, p. 183.

(3) Ibid., juillet 1866, p. 172.

(4) Pierre Albertini: L'école en France au XIX ${ }^{e}$-XX $X^{e}$ siècle, Paris, Hachette, 1992.

(5) Discours du grand-maitre adjoint, lors de l'installation de la nouvelle loge L'École de la Morale, à Libourne, $B D G O D F$, août 1862, p. 350. 
ne cessent de croître et de multiplier» (1). L'influence d'Edgar Quinet (2) est ici très nette. Les francs-maçons qui s'expriment dans les loges ont lu ou entendu parler de L'Enseignement du peuple, édité en 1850 et réédité en 1860. Le philosophe, longtemps disciple de Victor Cousin, est anticlérical, anticatholique, mais n'est pas antireligieux (3). Il n'est pas non plus franc-maçon. C'est «la critique du catholicisme qui l'a conduit à la nécessité d'un enseignement et d'une éducation laïques» (4).

Les francs-maçons, qu'ils soient spiritualistes ou athées, se rejoignent ainsi pour réclamer la laïcisation des enseignants. Dans un article ayant pour titre «Protection à l'enseignement laïque», le très spiritualiste Journal des initiés (5), se plaint de l'impuissance des «pouvoirs laïques » à contrôler les "pouvoirs cléricaux », et demande à ses lecteurs de venir en aide à l'institution laïque et de signaler «les effets subversifs de tout genre qui sont la conséquence de l'éducation et de l'instruction données dans les établissements cléricaux ».

L'opposition au clergé trouve une nouvelle vigueur avec la violente querelle suscitée par la publication du Syllabus du Pape Pie IX, en décembre 1864. Ce texte est une charge violente contre les libres penseurs et contre les francs-maçons que le Pape appelle «la secte». Le Syllabus entraîne une véritable mobilisation du camp laïque. Jean-Marie Mayeur, peut à juste titre écrire qu'on n'insistera «jamais assez sur l'importance du Syllabus dans la montée du nouvel anticléricalisme républicain de la fin des années 1860 » (6). Nos sources montrent que l'attaque du Pape a entraîné l'adhésion à la francmaçonnerie d'un nombre important d'anticléricaux et de libres penseurs qui n'auront de cesse de travailler à la séparation de l'Église

(1) Le Monde maçonnique, septembre 1861, p. 313.

(2) De façon générale, «l'influence d'Edgar Quinet sur les «pères» de la laïcité française a été considérable. Jules Ferry lui a rendu plusieurs fois hommage. Il possédait, paraît-il, les œuvres complètes de Quinet, visiblement lues et abondamment annotées, dans sa bibliothèque». Daniel Lindenberg, introduction à Edgar Quinet: L'Enseignement du peuple, réédition, Paris, Hachette Pluriel, 2001, p. 25.

(3) Pour Patrick Cabanel (Les Protestants et la République, Paris, Éditions Complexe, 2000, p. 53), Quinet «témoigne pour une gauche sensible au religieux, mais désespérant à jamais du catholicisme».

(4) Laurence Loeffel: La question du fondement de la morale lä̈que sous la Troisième République (1870-1914), Paris, PUF, 2000, p. 34.

(5) Le Journal des initiés, avril 1862, p. 161.

(6) Jean-Marie Mayeur: La question laïque, XIX ${ }^{e}-X X^{e}$ siècle, Paris, Fayard, 1997. 
et de l'École. On peut citer, à l'appui de cette affirmation et parmi d'autres faits, l'ouverture significative de la loge La Libre-pensée d'Aurillac, en 1865, qui est l'occasion d'un discours sans ambiguïté, reproduit, pour que le message soit clair, dans l'organe officiel de l'Ordre: «De nouvelles loges se fondent, celles qui s'étaient endormies se réveillent, les préjugés se dissipent comme de légers nuages [... la franc-maçonnerie] pousse de vigoureux rameaux qui sauront s'unir et s'entrelacer pour la défendre vaillamment contre les empiétements de l'intolérance, du fanatisme, de l'ignorance et de l'hypocrisie» (1).

Le Grand Orient et ses loges utilisent alors les attaques maladroites de l'Église pour mettre en valeur leurs propres actions. On peut même aller jusqu'à dire que les attaques cléricales qui les visent renforcent l'ardeur des francs-maçons dans leur opposition à l'Église, à laquelle ils renvoient d'ailleurs le reproche de pouvoir occulte en direction des mères, des femmes et des filles. On arrive ici à un autre thème cher aux francs-maçons de cette époque, l'instruction des filles: «N'est-ce donc rien que cette influence occulte qui s'exerce sur nos mères, nos femmes, nos filles, et qui, portant le trouble dans leur conscience, n'amène que trop souvent le désaccord dans la famille? N'est-ce donc point enfin un danger pressant, auquel il faut porter remède, que l'invasion de l'enseignement clérical dans nos campagnes au plus grand préjudice de l'enseignement laïque qui a d'autant plus besoin d'être soutenu, protégé, qu'il subit presque toujours une opposition dangereuse, insurmontable, parce qu'elle s'exerce d'une manière occulte qu'il est rarement possible de déjouer [...]. Il est plus que temps de développer l'instruction populaire à tous les degrés » (2).

\section{Quelle morale enseigner dans une école séparée de l'Église?}

Mais le projet d'un nombre grandissant de francs-maçons est également de promouvoir une «morale indépendante» de la religion. Or, pour beaucoup de contemporains, «l'idée d'une morale non confessionnelle dépourvue de fondement est impensable. Ou la morale est religieuse, et elle n'a pas à rendre compte de la légitimité de ses principes, ou elle ne l'est pas et se pose alors la question de son

(1) $B D G O D F$, septembre 1865, p. 452.

(2) $B D G O D F$, novembre-décembre 1866, p. 564. 
fondement, c'est-à-dire de la justification intime de ses prescriptions» (1). Autrement dit la question se pose de savoir s'il y a une alternative à la morale religieuse. Quinet dit clairement quelle est la nature du débat: "Qu'est-ce en soi la question de l'enseignement? Une question de direction morale. Tout se réduit à demander où est désormais le principe d'autorité. On répond: dans la religion. J'accepte cette réponse, mais j'insiste et je demande à mon tour: quelle religion? Il est trop manifeste que nulle autorité ne peut s'établir sur le principe de trois ou quatre cultes qui, se niant mutuellement, se détruisent l'un par l'autre. Asseoir la société française sur cette base, c'est l'asseoir dans le vide sur le trépied de l'éternelle anarchie» (2).

La question de la morale indépendante va beaucoup occuper les francs-maçons à la fin du Second Empire. Alexandre Massol (3) est, sans conteste, le plus actif sur le sujet. Il faudrait pouvoir s'attarder davantage sur ce personnage, aujourd'hui largement oublié (4). Massol a eu une influence considérable, les documents de l'époque le montrent, non seulement au sein de la franc-maçonnerie mais, plus largement, parmi les libres penseurs et les républicains. C'est, en fait, un des rares intellectuels à la fois francs-maçons et républicains à avoir un réel rayonnement sous le Second Empire.

Chez les francs-maçons, le souci d'une morale indépendante des religions apparaît certes déjà sous la Restauration, mais il n'en reste pas moins que Massol est, à ce moment du Second Empire, le meilleur théoricien franc-maçon de la morale indépendante et son propagateur infatigable. Il édite à partir de 1865 une revue qui prend d'ailleurs pour nom La Morale indépendante. Massol et ses amis sont soutenus par Le Monde maçonnique qui leur ouvre largement ses colonnes. Pour ce journal, dirigé par François Favre et pour les libres

(1) Laurence Loeffel, op. cit., p. 2.

(2) Edgar Quinet, op. cit., p. 36.

(3) Voir Adrien Desprez: La franc-maçonnerie contemporaine, Massol, Paris, 1865.

(4) Alexandre Massol est né à Béziers en 1805 et mort à Paris en 1875. C'est un philosophe, disciple de Saint-Simon et d'Enfantin. Il a été le collaborateur de Proudhon, dont il est l'exécuteur testamentaire. Il devient en 1863 Vénérable de la loge parisienne La Renaissance. Convaincu, comme Proudhon, que la franc-maçonnerie devait «se situer au-dessus des religions et pratiquer la raison libre» (A. Combes, $o p$. cit., p. 27), il fonde en 1865 la revue La Morale indépendante avec des collaborateurs francs-maçons comme Brisson et Caubet, ou non maçons comme Jules Barni. 
penseurs, la réponse, dès 1865 , ne fait pas de doute: l'enseignement de la morale ne doit pas être seulement indépendant des prêtres mais aussi de la religion.

Grâce à sa revue, Massol va, pendant une dizaine d'années, faire œuvre de vulgarisateur des principes de la morale indépendante avec une énergie peu commune et avec un talent certain. On va le voir effectuer de nombreuses conférences au sein de sa loge bien sûr, mais aussi un peu partout en France (1). Il répond à bon nombre d'invitations d'autres ateliers qui lui demandent des interventions. Et, quand il ne peut se déplacer, ce sont ses articles que l'on commente. On trouve ainsi de multiples traces de cette action militante dans les archives des loges. À Tours, le Vénérable de la loge Les Démophiles lit en séance, le 17 septembre 1866, «un article de la morale indépendante signé Massol», et le 21 janvier 1867 «un article philosophique du frère Massol» (2).

Les discussions provoquées au sein des loges par Massol et les tenants de la morale indépendante sont très suivies par la presse maçonnique, le Bulletin du Grand Orient de France étant plus discret sur ce sujet. La prudente réserve, et même parfois la franche hostilité, de l'organe officiel de l'Ordre s'explique certainement par le souci des dirigeants de ne pas donner encore davantage de relief aux très vives polémiques qui voient le jour, à propos de la morale indépendante, entre les francs-maçons déistes et les tenants de la laïcisation de la morale. Alexandre Massol est ainsi violemment pris à partie par Riche-Gardon dans Le Journal des initiés, en tant que «négateur de la religion universelle» (3). Riche-Gardon engage même une campagne de presse accusant Massol de n'avoir jamais été initié! (4)

Le Monde maçonnique ouvre au contraire ses colonnes aux tenants de la morale indépendante qui peuvent de cette façon promouvoir l'idée qu'ils se font d'une morale sans Dieu. Malgré toute

(1) On sait que la revue de Massol, La Morale indépendante, est lue en province ( $c f$. Sudhir Hazareesingh, Vincent Wright, op. cit., p. 152).

(2) Archives de la loge Les Démophiles de Tours, BN FM3 736.

(3) Le Journal des initiés, février 1863, p. 29.

(4) Il y aura une enquête sur ce sujet diligentée par le Conseil de l'Ordre. Massol sera défendu par Fauvety, malgré leurs graves divergences. De fait, Massol n'a pu apporter la preuve de son initiation. Pour André Combes, le doute subsiste. Mais l'historien de la franc-maçonnerie estime fort probable que Massol a été initié lors de sa période saint-simonienne. 
l'énergie déployée, Massol et ses amis sont encore minoritaires en 1870 au sein du Grand Orient. Au Convent de 1870, il est candidat aux élections pour la Grande Maîtrise et n'obtient que 10 voix sur 292 votants (1).

Mais il reste à définir ce que sera concrètement cette morale découplée de la religion. On sait que la principale argumentation du clergé catholique de l'époque est qu'il n'est pas possible de concevoir une autre morale. Ce serait même prendre de gros risques pour la société que de se priver de la menace d'un châtiment divin. Ces objections sont évidemment connues des massoliens. Le débat qui se poursuit au sein de la loge La Rose du parfait silence l'atteste et permet de fixer un cadre, très inspiré du kantisme, au nouvel enseignement de la morale: «Nous enseignerons les droits et les devoirs de l'enfant et du citoyen, au nom de la liberté, de la conscience et j'ajoute de la raison, triple apanage de l'homme sur la terre, et encore au nom de la solidarité. Et nous croyons fermement que ceux qui ne céderaient point à ces autorités suprêmes, ne céderaient pas davantage à la menace des gendarmes du ciel...» (2).

Tel qu'il apparait ici, le projet des francs-maçons, comme celui que les républicains mettront en œuvre après 1879 , est finalement moins de fonder une «morale de substitution à la morale religieuse, mais d'établir les principes d'une morale pour tous, croyants et non croyants » (3). Pour mener à bien ce projet, les francs-maçons de $L a$ Rose du parfait silence ne voient qu' une issue: il faut « une institution laïque de cet enseignement de la morale». C'est urgent, car la jeunesse « de nos jours voit excités et entretenus ses mauvais instincts

(1) Sudhir Hazareesingh et Vincent Wright (op. cit., p. 154) pensent que «cette écrasante défaite est en partie la condamnation de l'homme et de sa notion "indépendantiste» de la morale [...]. Mais on ne peut douter qu'il s'agit également de rejeter l'idée confédérale d'un Grand Orient qui laisserait une complète liberté d'action à ses composantes locales et territoriales ».

(2) Renouvier ne dit pas autre chose, en 1864, dans son Introduction à la philosophie analytique de l'histoire: "Les idées morales sont logiquement antérieures aux idées religieuses chez l'homme, puisqu'elles sont manifestement essentielles à sa constitution interne, plus directement et immédiatement liées à la loi de sa vie et de ses rapports. On peut concevoir l'homme sans religion, et, de fait, il est ou devient quelquefois tel. Mais on ne saurait le représenter dépourvu de la notion de moralité ni de ses applications principales (bien ou mal entendues) de cette notion. », cité par MarieClaude Blais: Au principe de la République, le cas Renouvier, Paris, Gallimard, 2000, p. 93.

(3) Laurence Loeffel, op. cit., p. 9. 
par les plus funestes exemples ». Pour cela, il faut des maîtres solides et exemplaires: "Que partout, au village comme dans la cité, des voix autorisées se fassent entendre et lui révèlent à cette jeunesse égarée mais non corrompue, la dignité de l'homme, ses droits, ses devoirs, la règle du bien et du mal; que des nobles accents ravivent au fond des âmes l'amour du juste, du beau, du grand, et le culte de l'honneur; que des instituteurs d'élite, glorifiant l'homme de bien, exaltent sa félicité et fassent craindre le supplice du remords; qu'ils mettent au plus haut prix, après les satisfactions de la conscience, les témoignages de sympathie et d'estime publique; qu'enfin ces honorables maîtres, indiquant la marche ascendante de l'humanité, annoncent les heureux destins et la gloire qui l'attendent sous le règne souverain de la justice et de la vérité; et, n'en doutez pas, mes frères, une transformation morale s'accomplira...».

On touche ici un domaine très délicat: le droit des familles à l'égard de leurs enfants. Sur ce sujet les débats sont souvent vifs. Un exemple caractéristique est la discussion qui entraine la loge L'École mutuelle (1), de Paris, dans une série de réunions dont la presse maçonnique rend compte. La question posée aux membres de cet atelier éclaire sur les préoccupations des francs-maçons à la fin du Second Empire: «quels sont les droits et les devoirs des parents à l'égard de leurs enfants au point de vue de l'enseignement religieux; un père a-t-il le droit d'élever son fils dans le culte d'une religion positive quelconque?». Pour certains francs-maçons, précise le journal, «bourrer l'esprit de l'enfant de fictions théologiques et de conceptions métaphysiques, est un acte de violence désavoué par la raison et contraire à la liberté humaine. On leur répondait que le père de famille avait non seulement le droit, mais aussi le devoir de faire élever son fils dans sa propre croyance, c'est-à-dire dans celle qu'il pratiquait sincèrement» $(2)$.

(1) L'École mutuelle est l'exemple d'une loge née d'une scission provoquée au sein d'une loge (Isis Montyon en l'occurrence) par des francs-maçons accusés de faire de la politique. Cette loge, créée en 1865 par des intellectuels autour de l'avocat André Rousselle, accueille des futurs parlementaires comme Dréo, Tirard, Delattre, Méline, l'écrivain Jules Claretie, Hendlé, futur préfet de Gambetta, Gustave Francolin, le directeur de La Réforme politique et littéraire créée en 1865 et plus tard (en 1878) de L'École nouvelle dont nous reparlerons. André Combes, «Des loges activistes du Grand Orient de France et de leur influence au sein de l'Obédience», Chroniques d'histoire maçonnique, janvier 1980, p. 56.

(2) Le Monde maçonnique, mars-avril 1868, p. 710. 
En lisant entre les lignes de ce compte rendu, on imagine la vigueur de la discussion, d'autant plus que le journal précise qu'elle a été si «ardente» et les «avis tellement partagés» que le débat se poursuit plusieurs réunions de suite. Il faut convenir que la question est d'importance: comment articuler et concilier le droit des parents et celui des enfants? Le Monde maçonnique croit d'ailleurs bon de préciser que «c'est la première question sur laquelle les membres de L'École mutuelle ne se soient pas encore mis d'accord».

Progressivement, l'idée que les programmes d'enseignement doivent être laïcisés gagne du terrain au sein du Grand Orient de France, à mesure d'ailleurs que les déistes quittent l'Obédience. Mais cela suscite encore bien des réticences. On peut ainsi lire dans $L a$ Chaîne d'Union, sous la plume de son directeur, Esprit-Eugène Hubert, un proche de Jules Simon: «L'enseignement laïque, c'est l'État enseignant. Ce n'est point dire que l'idée de Dieu doive être écartée de cet enseignement, car il n'y a pas d'enseignement sans des leçons de morale; or, il n'y a pas de morale qui puisse se tenir sur ses jambes sans l'aide de la proclamation et de la reconnaissance d'un principe immatériel supérieur. Toute morale ou toute prétendue morale qui veut venir de la terre et mourir sur la terre est un leurre ou quelque chose de plus terrible dont ce siècle a donné des exemples si néfastes et si lamentables: la force prime le droit» (1). C'est exactement cette position que défendra Jules Simon en 1879, contre Jules Ferry. C'est aussi pour cela que, quelques années plus tôt, Jules Simon alors ministre de Thiers fit rétablir le catéchisme dans les écoles de Paris et «fit prendre des sanctions contre les instituteurs de Lyon qui ne l'enseignaient plus» (2).

Mais ce qui se dit en 1874 dans un discours prononcé lors d'une réunion de la loge L'Étoile de Chaumont illustre bien une tendance qui deviendra majoritaire au Convent de 1877: «Il faut que l'instruction soit mise à la portée de tous; l'enfant lui-même doit être mis dans l'obligation d'aller chercher gratuitement dans les écoles civiles, une instruction qui sera, avec la nourriture de son esprit, la sauvegarde la plus certaine de la liberté et de la morale publique; mais cette instruction doit être purement laïque; par ce mot, je veux, non pas seulement qu'elle soit donnée par des laïques, mais qu'elle

(1) Ibid., janvier 1873, p. 63.

(2) Pierre Chevallier: La Séparation de l'Église et de l'École, Paris, Fayard, 1981, p. 65 . 
soit donnée sans aucune ingérence des idées religieuses. L'éducation religieuse regarde les familles et n'a rien à faire avec l'école proprement dite» (1).

\section{Jean Macé et le conflit à propos de la laïcité}

Le premier article de fond consacré à la Ligue de l'enseignement, signé du rédacteur François Favre paraît en mai 1867 dans Le Monde maçonnique. Dans un long développement, les francs-maçons sont invités à apporter tout leur concours à «cette œuvre de pacifique émancipation et de progrès intellectuel», dont l'objet est rappelé: «la propagation, la vulgarisation, non seulement de l'enseignement primaire, premier et indispensable échelon des connaissances humaines, mais de toutes les sciences et de tous les arts que peut embrasser le génie de l'homme» (2). Le premier cercle de la Ligue est fondé à Metz, le 21 juin 1867 par Edmond Vacca, professeur de physique au lycée de la ville, ami personnel de Jean Macé et vénérable de la loge Les Amis de la Vérité (3). Cette création suscite une très vive hostilité de la part de l'évêque de Metz, $M^{\text {gr }}$ Dupont des Loges, qui voit dans la Ligue un «œuf de franc-maçon» (4). L'évêque rédige immédiatement un mandement épiscopal qui désigne sans équivoque la francmaçonnerie comme responsable de l'apparition de la Ligue: «Nous croirions manquer à un devoir essentiel de notre charge pastorale si nous ne signalions pas à vos défiances une institution récente qui vient de se former dans notre ville épiscopale sous la dénomination de Cercle messin de la Ligue de l'Enseignement [...]. Semblable au Protée de la fable, la franc-maçonnerie sait multiplier à l'infini ses transformations et ses noms: hier elle s'appelait les Solidaires ou la Morale indépendante ou la Libre-pensée; aujourd'hui elle s'appelle la Ligue de l'Enseignement; demain elle empruntera quelque autre titre pour abuser les simples»(5). Après l'article de soutien du

(1) Archives de la loge, BN HP 1796. Cité par Gérard Gayot: La Franc-maçonnerie française, Paris, Julliard, 1980, p. 108.

(2) Le Monde maçonnique, mai 1867, pp. 56 - 60.

(3) Pierre Barral: La Franc-maçonnerie en Lorraine au XIXe siècle, Nancy, Berger-Levrault, 1970, p. 21.

(4) La formule sera reprise un peu plus tard par Jean Macé à l'occasion d'un discours prononcé dans la loge de Strasbourg.

(5) In Maurice Gontard: L'œuvre scolaire de la Troisième République, Toulouse, CRDP, 1976, p. 197. 
Monde maçonnique, plusieurs lettres parviennent au journal pour annoncer des adhésions de loges, à Paris et à Valence, en juin et juillet 1867. Très régulièrement, ensuite, le journal donne des informations sur les adhésions maçonniques. C'est ainsi qu'en mars 1868, Le Monde maçonnique nous apprend qu'il est informé par «le frère Macé» (1) que 17 loges sont entrées à cette date dans la Ligue, et que le cercle de Metz, en pleine activité, «compte déjà 545 membres et la bibliothèque a reçu 703 volumes de divers donateurs » (2).

Au total, cela fait assez peu de loges engagées au sein de la Ligue de l'enseignement dans les deux premières années, à peine $10 \%$ selon notre estimation, mais cela ne signifie pas que les francs-maçons ne se soient pas engagés à titre individuel. Et même si le Monde maçonnique signale à ses lecteurs, en avril 1868, «que les loges souscrivent de plus en plus nombreuses à la Ligue de l'enseignement dont le frère Jean Macé a eu l'initiative», on ne peut donc pas dire que l'apport des loges ait été déterminant pour le lancement de la Ligue. Nous relevons, de plus, que le Conseil de l'Ordre est pratiquement muet à cette période sur la Ligue de l'enseignement. Nous n'avons trouvé que quelques rares allusions, que l'on ne peut considérer comme un soutien officiel. La quasi-absence de relais dans Le Bulletin du Grand Orient de France n'est pas, à l'évidence, de nature à susciter un fort engagement des loges. On peut penser que les dirigeants du Grand Orient, mobilisés par le projet de création de leur propre œuvre d'enseignement (projet qui a échoué), n'ont pas souhaité détourner l'attention des loges vers un projet d'origine profane. On peut aussi surtout imaginer que le Conseil de l'Ordre ne tenait pas à déplaire au gouvernement. Napoléon III «n'autorise pas la Ligue à ses débuts. Duruy lui-même se méfiait d'un zèle qu'il jugeait indiscret et ne dispensa guère d'encouragements » (3).

Pourtant, malgré la timidité des loges, la Ligue doit faire face à de violentes attaques du clergé sur sa supposée origine maçonnique. Comme exemple significatif, on peut citer l'article de $\mathrm{M}^{\mathrm{gr}}$ Dupanloup, dans Le Siècle: «Ce n'est point une Ligue de l'enseignement, c'est une Ligue contre la religion catholique [...]. La

(1) Jean Macé a été initié le 2 mars 1866 dans la loge La Parfaite harmonie de Mulhouse.

(2) Le Monde maçonnique, mars 1868, p. 615.

(3) Françoise Mayeur: Histoire générale de l'enseignement et de l'éducation en France, tome 3, Paris, Nouvelle Librairie de France, 1981, p. 269. 
Ligue n'est qu'un moyen de répandre les ténèbres de la franc-maçonnerie. Cela seul vous condamne. Vous cherchez autre chose que les progrès de l'instruction. Vous croyez naïvement enrégimenter dans votre secte antireligieuse et antisociale certains instituteurs. Sachezle, les campagnes résisteront. Vous y êtes connus et si vous faites des adeptes, ce ne sera que parmi les sots, les plus sots et les tarés » (1).

Dans le troisième numéro du bulletin de la Ligue, Jean Macé se défend de ces accusations, et fait le point sur le nombre de loges ayant adhéré à la fin de 1868. Cette mise au point, très utile pour mesurer l'impact du soutien maçonnique, est reproduite dans Le Monde maçonnique (2): «ce n'est pas la franc-maçonnerie qui a fait la Ligue», se défend Jean Macé, «ce sont les 5319 adhérents qui s'étaient ralliés à l'idée quand j'ai clos la liste préparatoire le 23 mars dernier». Pour Jean Macé, c'est «rapetisser» la Ligue si on la «fait sortir d'un mot d'ordre donné quelque part. Elle est sortie des entrailles mêmes du pays, et celui qui l'a provoqué n'avait reçu consigne de personne, n'a pris conseil que de lui-même quand il s'est décidé à lancer l'appel». Il faut se souvenir de ces paroles quand, après 1879 et dans un tout autre contexte politique, Jean Macé dit le contraire à plusieurs reprises. Notre sentiment est qu'on a, par la suite, eu trop tendance à privilégier les déclarations effectuées après la victoire républicaine et à oublier les propos initiaux. Même si, à ce moment, Jean Macé visite des loges pour gagner leur soutien (3), il tient à se défendre contre les attaques du parti clérical qui met en avant l'appui qu'il reçoit du Monde maçonnique. Jean Macé précise que ce journal n'est pas le seul, et que si des loges figurent sur des listes d'adhérents, elles n'ont apporté «à l'œuvre de tout le monde qu'un appoint, utile il est vrai, mais insuffisant pour qu'on puisse la leur attribuer».

Jean Macé fait d'ailleurs remarquer que les adhésions des loges ont été plutôt lentes à venir, ce qui est la réalité, nous l'avons vu, et il prend soin de préciser que «les adversaires de la franc-maçonnerie le

(1) Le Siècle, 14 août 1868, cité par Maurice Gontard, op. cit.

(2) Le Monde maçonnique, décembre 1868-janvier 1869, pp. 569 et suivantes.

(3) L'effort de Jean Macé pour utiliser le réseau des loges est en effet très visible. Par exemple, en septembre 1868, il est présent au congrès des loges de l'Ouest et encourage la création d'une école laïque pour les jeunes filles. Cela lui vaut les félicitations du Monde maçonnique de septembre-octobre 1868, p. 368 : «Nous félicitons très sincèrement le F. Macé de cette heureuse initiative. Dans cette voie, dans la voie de l'enseignement laïque et anticlérical, il peut être assuré de la sympathie et du concours des libres penseurs». 
savent aussi bien que ses amis». Jean Macé souhaite également s'adresser «aux citoyens qui ont accepté pour leur compte l'œuvre et les principes de la Ligue» en espérant qu'ils «n'abandonneront pas le travail commencé pour avoir appris que c'est un travail maçonnique». On voit ici le souci du fondateur de la Ligue de l'enseignement d'ouvrir largement le recrutement de son association, y compris aux catholiques.

C'est cette question des adhérents de la Ligue qui va être l'occasion d'un sévère conflit avec les francs-maçons libres penseurs et laïques rassemblés autour du journal Le Monde maçonnique. Elle peut aussi expliquer le relativement faible engagement maçonnique dans les débuts de la Ligue. On sait que Jean Macé est très réservé sur l'emploi du mot laïcité. Il préfère le mot de neutralité, car sa priorité est d'abord la mise en œuvre de l'obligation scolaire (1). Conformément au souhait de Jean Macé, des catholiques, peu nombreux il est vrai, sont d'ailleurs membres de la Ligue dans les premiers temps. Cette attitude n'est pas du goût des francs-maçons du Monde maçonnique. Une vive polémique s'engage alors entre le journal et la Ligue. En étudiant la presse maçonnique, nous avons pu en reconstituer les différents moments.

Il convient, au préalable, de rappeler que le débat est d'autant plus vif qu'il recouvre, comme on le sait, un débat interne à la francmaçonnerie. En effet, les fondateurs de la Ligue, Macé, Vauchez, Martin et Sauvestre sont déistes (2) et veulent, tout en s'appuyant sur les loges, "promouvoir un rassemblement plus large, plus œcuménique pourrait-on dire» (3). Encore minoritaires au sein des loges, mais engagés dans la laïcisation du Grand Orient, les francs-maçons libres penseurs du Monde maçonnique vont faire pression sur leur frère Jean Macé pour tenter de laïciser la Ligue. Et l'on retrouve donc ici la division entre francs-maçons athées et spiritualistes évoquée plus haut. Jean Macé est, dans un premier temps, violemment interpellé par François Favre: "Quel rôle la franc-maçonnerie est-elle donc appelée à jouer dans cette ligue bigarrée, composée des élé-

(1) Jean-Paul Martin, op. cit., p. 35.

(2) Selon Françoise Mayeur (op. cit., p. 268), Jean Macé est d'une religiosité profonde, «mais il s'oppose au clergé qu'il estime incompétent pour répondre aux besoins religieux de l'époque».

(3) Jean-Paul Martin, op. cit., p. 36. 
ments les plus divers, les plus disparates, les plus hostiles?» (1) L'accusation tombe: "Ainsi que le frère Macé a bien voulu le rappeler, Le Monde maçonnique a recommandé la Ligue à ses débuts, concours imparfait dans ses résultats assurément, et qui n'aurait jamais été donné si l'on avait pu supposer un seul instant que le but réel de l'œuvre n'était pas de propager exclusivement l'enseignement laïque». Jean Macé est expressément invité à «repousser toutes les accointances et toutes les alliances compromettantes», de «prendre parti» et de «quitter cette allure incertaine, qui rappelle le paysan ivre de Luther, penchant tantôt à droite, tantôt à gauche». La conclusion est posée en termes encore plus durs: «La Ligue ne peut réussir, elle ne trouvera d'appui sérieux, dans la franc-maçonnerie ou ailleurs, que lorsque ses promoteurs se seront déclarés franchement pour l'un des deux compétiteurs qui s'en disputent déjà la direction: le cléricalisme et la libre pensée. En voulant les contenter tous deux, on mécontente tout le monde. Trop d'habileté nuit, parfois; et la conduite la plus droite est bien souvent la plus adroite». François Favre demande enfin à Jean Macé de répondre à cette question: "La Ligue a-t-elle pour but de propager exclusivement l'enseignement laïque ou, indifféremment, l'enseignement laïque et l'enseignement clérical?».

La réponse de Jean Macé et de ses proches s'organise en deux temps. C'est tout d'abord le rédacteur de L'Opinion nationale et ami de Jean Macé, Charles Sauvestre, qui utilise les colonnes de son journal (2) pour rappeler, avec une perfidie non dissimulée, que «le journal de M. Favre ne représente qu'une fraction peu nombreuse de l'association maçonnique», ce qui est vrai, en 1868, on le sait. Sauvestre fustige la position du Monde maçonnique qui s'en prend, ajoute-t-il, à Jean Macé et à la Ligue, «pour ne s'être pas déclarés athées, pour avoir voulu respecter la liberté de conscience et maintenir la Ligue dans une direction étrangère à tout esprit de secte, à tout esprit de parti. [...] Voici la Ligue de l'enseignement bel et bien excommuniée, et presque le même jour, par les fanatiques ultramontains et par les fanatiques de l'athéisme. Espérons qu'elle ne s'en portera pas plus mal».

(1) Le Monde maçonnique, décembre 1868-janvier 1869, pp. 569 et suivantes.

(2) La réponse de Charles Sauvestre est publiée par Le Monde maçonnique dans le numéro précédemment cité, p. 587. 
Le 2 février, L'Opinion nationale publie la réponse de Jean Macé (1). Le fondateur de la Ligue commence par réfuter le mot laïque: «Il n'y a pas de place, dans le programme de la Ligue, pour le mot «d'enseignement laïque » qu'on prétend lui imposer pour établir, malgré elle, un antagonisme qui n'est pas, et ne sera pas de son fait, s'il existe». Jean Macé donne ensuite sa définition de l'enseignement voulu par la Ligue: «L'enseignement qu'elle entend donner étant placé en dehors de toute discussion doctrinale, ne saurait accepter d'autre nom que celui d'enseignement scientifique. Or, la science n'est ni laïque, ni cléricale: elle est la science. La lecture, l'écriture, le calcul, la tenue des livres, la géométrie, la géographie, l'astronomie, la chimie, l'histoire universelle, l'hygiène, le droit usuel, l'étude des langues étrangères, tout ce qui peut faire l'objet de cours ouverts par les cercles de la Ligue, tout cela n'a que faire de s'affubler d'une étiquette contraire à l'esprit qui les anime. Un ecclésiastique qui se présenterait pour les enseigner, sous la condition que nous avons posée de ne pas en faire un prétexte à polémique, serait admis très positivement». Enfin, la Ligue «n'exclut personne» et ses écoles «seront ouvertes à tous les cultes». On y laissera «aux parents le soin de veiller eux-mêmes à l'enseignement religieux de leurs enfants». Si l'on fait la somme de toutes les conditions posées par Jean Macé, on s'aperçoit que sa construction ressemble bien, en fait, à un enseignement laïque. Jean Macé le reconnaît implicitement en déclarant, à la fin de sa réponse, «ces conditions, aucune congrégation religieuse ne saurait les accepter, c'est assez clair».

La réponse de Jean Macé convient au Monde maçonnique, qui y voit l'indice que le frère Macé «revient à la vie réelle, vie de luttes et de divisions, pour dire avec raison qu'aucune congrégation religieuse ne saurait accepter les conditions de la Ligue. Par conséquent, la Ligue se place, par le fait, en antagonisme avec l'enseignement clérical. Et, en vérité, c'est bien heureux pour elle» (2). Cette polémique, intégralement publiée dans le journal maçonnique, a évidemment eu des lecteurs. Soucieux, semble-t-il, de donner l'image d'un journal ouvert à d'autres opinions, Le Monde maçonnique publie la réaction de la loge Tolérance et Progrès de Lure, en Haute-Saône, une des premières loges à avoir adhéré à la Ligue pour la somme de $20 \mathrm{fr}$. le 7 octobre 1867. Le Vénérable de la loge dit tout net à François Favre qu'il ne partage pas son point de vue et donne une leçon de réalisme:

(1) Ibid., pp. 588-589.

(2) Ibid., p. 590. 
«la loge n'a pu admettre votre manière de voir et de juger». Jean Macé, poursuit-il, agit «franchement et loyalement» et a bien mérité «non seulement de la maçonnerie mais de l'humanité, en sacrifiant sa santé, son temps et ses intérêts à la diffusion de l'instruction». Le journal du frère Favre est taxé d'intolérance, «à ne pas admettre qu'une œuvre pût à la fois être maçonnique et profane. [...] Les membres de la loge n'admettent conséquemment pas l'exclusivisme mais l'association libre, ils n'admettent pas seulement des théories, mais la pratique et surtout les faits. Or, le frère Jean Macé leur a paru un homme essentiellement pratique et s'appuyant sur les faits; par suite, la loge l'a soutenu, le soutiendra et fera tous ses efforts pour que la maçonnerie lui prête son concours» (1).

\section{Une expression tardive des organes dirigeants sur la laïcité}

La première prise de position officielle du Grand Orient en faveur de la laïcité de l'instruction date du Convent de juin 1870. Il faut préciser que, à un moment où le rapport des forces au sein de l'Obédience entre croyants et non-croyants était encore incertain, ce soutien maçonnique n'a, semble-t-il, pas été prémédité. En effet, il était apparemment prévu à l'origine de faire simplement voter par l'assemblée maçonnique «une proposition de pétitionnement concernant l'instruction gratuite et obligatoire dont l'initiative appartient à la loge de Strasbourg». Le Bulletin officiel du Grand Orient nous apprend que cette proposition est accueillie «par les plus vifs applaudissements ». Des francs-maçons, estimant sans doute que la proposition n'allait pas assez loin, «demandent qu'après le mot obligatoire, il soit ajouté le mot laïque» (2). L'assemblée se lève, nous indique le compte rendu officiel, "d'enthousiasme et adopte à l'unanimité». Devant cet élan manifestement suscité par un groupe de délégués très décidés, le Grand Maître Babaud-Laribière ne peut qu'obtempérer. Le Convent décide aussitôt d'adresser sa résolution «à M. Jules Simon pour être déposée sur le bureau du Corps législatif à l'appui des pétitions dont il doit incessamment faire le dépôt, à l'occasion du projet de loi sur l'enseignement ».

Globalement, les francs-maçons sont d'accord pour repousser les dogmes religieux et les clercs dans la sphère privée et les faire sortir

(1) Le Monde maçonnique, février-mars 1869, pp. 594-595.

(2) BDGODF, juillet 1870, pp. 296-297. 
de l'école publique. Mais le clivage s'opère entre ces anticléricaux dès que la place du Grand Architecte entre dans la discussion, surtout à propos de la morale. Ce n'est pas parce qu'ils «acclament» le principe d'enseignement laïque au Convent que les francs-maçons ont réglé cette difficulté majeure qui ressortira ultérieurement. A minima, ce qui rassemble les francs-maçons, c'est la lutte contre l'ennemi commun, le clergé catholique, et l'objectif à atteindre c'est la séparation de l'Église et de l'École. Le journal L'Action maçonnique résume bien le sentiment général chez les francs-maçons de la fin du Second Empire: "Nous n'aurions rien fait, si nous ne parvenions pas à arracher d'une manière définitive nos enfants à l'enseignement religieux » (1).

\section{LE DÉBAT LÉGISLATIF SUR LAÏCITÉ : LES FRANCS-MAÇONS ACTEURS EN POLITIQUE}

\section{Les francs-maçons au ministère de l'Instruction publique}

\section{L'initiation de Jules Ferry}

Jules Ferry est initié en juillet 1875, au sein de la loge $L a$ Clémente amitié dont le Vénérable est Charles Cousin, vice-président du Conseil de l'Ordre. L'initiation lors de la même cérémonie de Littré, ancien disciple de Comte (jusqu'en 1851), et de Jules Ferry, tous deux membres de l'Assemblée nationale, en compagnie du professeur de linguistique Honoré Chavée, produit un très grand effet dans et hors de la franc-maçonnerie. Cette initiation est organisée en présence de très nombreux responsables républicains, mais en l'absence de Jules Simon qui avait envoyé une lettre d'excuse (2). Cet épisode marquant de l'histoire de la franc-maçonnerie a déjà été étudié par Louis Legrand (3) et par Pierre Chevallier (4), et par conséquent nous n'en retiendrons que les enseignements qui permettent d'éclairer cet article.

(1) L'Action maçonnique, 15 septembre 1868, p. 324.

(2) Louis Capéran: Histoire contemporaine de la laïcité française, Paris, Marcel Rivière, 1960, tome 1, p. 10.

(3) Louis Legrand: L'influence du positivisme dans l'œuvre scolaire de Jules Ferry, Paris, Marcel Rivière, 1961.

(4) Dans La Séparation de l'Église et de l'École, op. cit. 
Tout d'abord, ces initiations sont interprétées comme une aide mutuelle que s'apportent les francs-maçons et les positivistes dans leur lutte contre le cléricalisme. Il s'agit, de notre point de vue, d'une association que l'on peut qualifier d'équilibrée dans la mesure où les positivistes apportent la base philosophique qui manquait aux francsmaçons pour mener leur combat, et où le Grand Orient, en lui ouvrant ses loges, met à la disposition de la doctrine positiviste le réseau dont avait besoin cette dernière pour mieux se faire connaître.

Mais en organisant ces initiations en plein ordre moral, et quelques jours avant le vote de la loi sur la liberté de l'enseignement supérieur (1), le Grand Orient de France contribue également à fédérer les républicains de diverses tendances (Littré et Ferry appartiennent à la droite du parti républicain) et apporte ainsi une contribution essentielle à la préparation de la bataille politique à venir.

S'il est permis de penser que Jules Ferry a d'autant plus songé entrer dans la franc-maçonnerie que les idées positivistes se répandaient largement dans les loges, on ne peut non plus exclure un calcul plus politique du futur ministre. Notons qu'avant 1870, Jules Ferry était encore pour le moins réservé et souvent critique à l'égard de la franc-maçonnerie et des francs-maçons. Ainsi, au moment des élections de 1869, Ferry a été en contact avec des francs-maçons parisiens. Dans une lettre à Edgar Quinet, il porte cette appréciation: «Le haut du pavé est à l'heure qu'il est à un jacobinisme ombrageux, qui se croit maître du monde, qui lance l'anathème à ceux qu'il appelle - il faut voir de quel ton méprisant - les libéraux girondins. Vous connaissez, du reste, cette faction de mon parti, vous savez combien leur cervelle est étroite, si leur cœur est bon. Ce qui les caractérise, c'est une sorte d'illuminisme et de mauvaise humeur, qui leur fait voir les choses autrement qu'elles ne sont, et persuade qu'il n'y a qu'à faire certains signes maçonniques, à prononcer certaines formules vagues et à crier Vive la République! pour que la République se fasse $! . . . »(2)$.

Autre exemple du jugement plutôt sévère de Ferry en 1869 sur ceux qui seront bientôt ses frères, c'est la lettre écrite à Gambetta cette fois, et où il fait mention d'un dignitaire du Grand Orient en

(1) Le vote de cette loi «permet au parti catholique de remporter sa dernière grande victoire juridique en matière scolaire», P. Albertini, op. cit., p. 48.

(2) Lettre du 19 janvier 1869, cité par Pierre Chevallier, op. cit., p. 84. 
accusant ce dernier, avec les mêmes mots que dans la lettre à Quinet, de se contenter de pratiquer «une sorte d'illuminisme», de faire «certains signes maçonniques», et espérer ainsi «renverser l'Empire et instaurer la République» (1).

On peut donc comprendre pourquoi, se présentant à l'initiation à quarante-trois ans, Jules Ferry n'a pas été dispensé, lors de la cérémonie, d'un interrogatoire auquel ont voulu le soumettre des francsmaçons qui savaient très probablement à quoi s'en tenir sur les propos tenus par Ferry sur la franc-maçonnerie et qui avaient de la mémoire. La Chaîne d'union précise, en effet, que «seul M. Ferry a dû subir un interrogatoire auquel il a répondu à la satisfaction de tous». Nous ne connaissons pas les réponses de Jules Ferry mais nous savons quelles questions lui ont été posées par quelques frères méfiants: «Quel but il se proposait en entrant dans la Maçonnerie? Pourquoi il avait attendu jusqu'ici pour entrer dans la Maçonnerie?» (2).

Pierre Chevallier peut donc avancer avec quelque raison que l'entrée en franc-maçonnerie de Jules Ferry s'effectue «plus peut-être en raison d'une nécessité politique que d'un attrait vraiment sincère pour l'institution; donner son nom à la maçonnerie, en suivant l'exemple de Littré, émule à soixante-quinze ans, de Voltaire, c'était avant tout défier le parti conservateur et clérical, et se ranger derrière un drapeau hautement affiché»(3). Il rejoint en cela l'avis de Maurice Reclus qui considère que Jules Ferry a «été sollicité d'adhérer» non sans avoir résisté «par souci d'indépendance naturelle (ne vous mettez jamais derrière personne était un conseil qu'il donnait volontiers à la jeunesse), par crainte d'avoir à abdiquer ses idées personnelles, par répugnance du légiste à faire partie d'un groupement à caractère «secret». L'insistance de certains hauts dirigeants des loges qui tenaient à s'assurer cette recrue sensationnelle finit par avoir raison de ses hésitations » (4). Ajoutons qu'on ne peut pas non plus oublier que Jules Ferry est initié dans la loge Alsace-Lorraine, loge où la famille Risler est influente, à quelques semaines justement de son mariage avec Eugénie Risler.

(1) In Pierre Chevallier, op. cit., p. 84.

(2) La Chaîne d'union, op. cit., p. 545.

(3) Pierre Chevallier, op. cit., p. 85.

(4) Maurice Reclus: Jules Ferry, 1832-1893, Paris, Flammarion, 1947, p. 118. 
Par ailleurs, l'appartenance au réseau maçonnique peut être utile à qui veut s'implanter électoralement. Dans une lettre à son épouse, datée de 1889, Ferry dira d'ailleurs le soin particulier qu'il apporte au contact avec la loge d'Épinal, même si l'on sent dans son propos qu'il le fait sans enthousiasme: «La douce monotonie du Conseil général est recommencée. Déjeuner chez le préfet, dîner chez Diener ou Mangin. Visiter la loge maçonnique - ce qui ne m'arrive qu'à Épinal y discuter des mérites comparatifs de la Constitution de 1875 et de celle des États-Unis, pour la plus grande joie des frères...» (1).

\section{Une présence modeste de la franc-maçonnerie au ministère}

La nomination du «frère» Jules Ferry au ministère de l'Instruction publique le 5 février 1879 n'est pas mentionnée, à notre connaissance, dans la presse maçonnique. C'est la revue L'École lä̈que du député franc-maçon Jean Saint-Martin qui évoque en ces termes la nomination de Jules Ferry: «Un nouveau ministre de l'Instruction publique a été nommé cette semaine, M. Jules Ferry. Nous aimons à nous rappeler que M. Jules Ferry est un libre-penseur qui s'est marié civilement et s'est allié à l'une des plus honorables familles de cette noble Alsace, une famille dans laquelle la libre pensée est de tradition et de principe. C'est d'un bon augure, et nous sommes sûrs que le Ministre du 5 février mettra, dans l'intérêt de la France, son influence et sa haute situation au service de ses idées qui sont, en matière d'instruction et d'émancipation populaires, celles de la majorité du pays» (2).

On voit ici que ce n'est pas le franc-maçon qui est salué, par prudence sans doute, mais plutôt le libre-penseur. L'allusion au mariage civil de Jules Ferry, mariage qui lui sera vivement reproché par la hiérarchie catholique, est significative de l'importance qu'accorde le camp laïque aux mariages et aux enterrements dans la procédure de laïcisation de la vie des citoyens. La presse cléricale ne s'y trompe pas qui attaque le «franc-maçon Ferry» autant que l'homme marié civilement: «Le franc-maçon Ferry!... Cet étrange ministre de l'Instruction publique qui n'est marié que civilement qui, par conséquent, n'est pas marié du tout et étale cyniquement son concubinage $»(3)$.

(1) Lettre du 4 juin 1889, citée par Jérôme Grévy: La République des opportunistes, 1870-1885, Paris, Perrin, 1998, p. 346.

(2) L'École laïque, 9 février 1879, p. 2.

(3) Le Poitou, cité par L'École lä̈que, 30 mars 1879, p. 15. 
Quant à la présence d'autres francs-maçons au ministère: il semble qu'il y en ait eu très peu dans l'entourage proche de Jules Ferry, lui-même franc-maçon peu actif, au ministère. C'est là un fort contraste avec la présence importante de protestants ou d'anciens protestants (Buisson, Pécaut...). Jules Ferry reconnaît d'ailleurs l'influence des protestants au sein de la République. Ainsi, quand il inaugure les nouveaux bâtiments de la faculté de théologie protestante de Paris le 7 novembre 1879, il salue les protestants «comme une puissance amie, comme un allié nécessaire, qui ne fera défaut ni à la République, ni à la liberté» (1). Les francs-maçons ne recevront jamais un tel hommage de la part de leur frère ministre.

$\mathrm{Au}$ ministère, les seuls collaborateurs francs-maçons de Ferry sont Jules Steeg, protestant, député de la Gironde et vice-président de la Ligue nationale pour la séparation des Églises et de l'État (2), dont l'appartenance maçonnique était déjà connue, et Alfred Rambaud, chef de cabinet de Jules Ferry dès 1879, dont notre recherche permet d'affirmer qu'il était bien franc-maçon, initié le 13 mars 1881 dans la même loge que son ministre, La Clémente amitié à Paris (3).

\section{Le poids des francs-maçons au Parlement}

À partir de 1878, on constate un double mouvement: l'élection de députés ou de sénateurs francs-maçons, d'une part, et l'initiation de parlementaires, d'autre part. Les adversaires de la franc-maçonnerie prennent l'affaire très au sérieux. Prenant en compte le fait que les candidats républicains aux élections de 1878 doivent accepter un mandat ainsi conçu: «il votera pour la laïcité absolue de l'enseignement à tous les degrés, lequel devra être obligatoire et gratuit », le publiciste catholique E. Davesne y voit, dans son opuscule, la preuve de l'influence maçonnique: "Il ne nous reste plus qu'un point à éclaircir: la Franc-Maçonnerie a-t-elle un programme en fait d'enseignement, et quel programme? À cette question, nous répondrons:

(1) Cité par Patrick Cabanel: Les Protestants et la République, Paris, Éditions Complexe, 2000, p. 73.

(2) André Combes, op. cit., tome 2, p. 159; Jacqueline Lalouette: La libre pensée en France 1848-1940, Paris, Albin Michel, 1997, p. 261, et Pierre Chevallier, op. cit., tome 3, p. 81 .

(3) Archives du Grand Orient de France, dossier de la loge Sincérité parfaite et Constante amitié réunies de Besançon, 1858-1889, boîte 686. 
oui, la Franc-Maçonnerie a un programme en fait d'enseignement et ce programme est précisément celui dont on poursuit en ce moment la réalisation. Il se résume en un mot: laïciser l'école obligatoire. [...] La Franc-Maçonnerie veut s'emparer de la jeunesse. C'est donc toute la Maçonnerie qui a engagé la lutte, c'est elle qui combat et ce sera elle encore, elle seule, et non la France, qui triomphera. [...] Catholiques, levons-nous donc au cri de «Arrière la Maçonnerie!». Fils des croisés, serrons-nous autour de notre drapeau et combattons pacifiquement, mais jusqu'à la mort, s'il le faut, contre les fils de Voltaire, pour l'avenir de la France et pour l'âme de nos fils !» (1).

Davesne publie en outre une liste de 21 sénateurs et de 74 députés francs-maçons en 1879. Nous trouvons un peu plus de députés francsmaçons que Davesne (79) et pratiquement le même nombre de sénateurs (20) (2). 72 noms de députés et 17 noms de sénateurs coïncident. À quelques erreurs près, le travail du publiciste donne donc une image relativement fidèle du poids des francs-maçons à la Chambre et au Sénat. Mais il n'est pas toujours possible de savoir si les parlementaires identifiés comme francs-maçons à un certain moment ont toujours une activité maçonnique lors des discussions législatives. Certains députés ou sénateurs peuvent très bien avoir été membres d'une loge plusieurs années auparavant, être connus comme francs-maçons à ce titre, et s'être éloignés de la franc-maçonnerie par la suite (la durée moyenne d'adhésion à la franc-maçonnerie n'était que de cinq à six ans à l'époque), sans que le chercheur ait les moyens de le savoir. Nous savons par ailleurs que l'activité maçonnique de certains est soit inexistante (Schoelcher) ou très peu visible (AllainTargé). La période d'activité maçonnique, Jacqueline Lalouette l'a bien montré, ne «correspond pas toujours, tant s'en faut, à celle où les fonctions politiques furent les plus nombreuses et les plus importantes» (3). Brisson, par exemple, ne fut franc-maçon actif qu'entre 1856 et 1870.

(1) E. Davesne: La Franc-Maçonnerie et les projets Ferry, Paris, 1879.

(2) Nous avons recoupé les résultats de notre recherche avec les indications des dictionnaires maçonniques (notamment le dictionnaire de Daniel Ligou et celui de Michel Gaudart de Soulages et Hubert Lamant), et des ouvrages des historiens de la franc-maçonnerie (tout particulièrement André Combes et Pierre Chevallier) et de la Troisième République. Voir la liste et les notices biographiques dans notre thèse, op. cit.

(3) J. Lalouette: «Francs-maçons et libres penseurs», in J.-M. Mayeur (dir.): Les parlementaires de la Seine sous la Troisième République 1. Etudes, Paris, Les Publications de la Sorbonne, 2001, p. 80. 
Le cas particulier du Président de la Chambre, Gambetta peut être considéré comme un bon exemple de ce doute. Gambetta est-il un franc-maçon actif en 1879? Nous ne le pensons pas. La loge de Marseille dans laquelle il a été initié en 1869 se met en sommeil en 1872. Les historiens de la franc-maçonnerie ne trouvent pas d'autre trace de Gambetta en tant que membre d'une loge alors que, compte tenu de la place tenue par Gambetta dans le monde républicain, une affiliation ultérieure dans une loge parisienne ne serait pas passée inaperçue (1). Sa présence, en 1875, lors de l'initiation de Littré et Ferry à La Clémente amitié ne suffit pas à prouver que Gambetta est un franc-maçon actif (2).

\section{Des parlementaires francs-maçons particulièrement présents}

L'analyse des débats permet tout d'abord de mesurer la proportion de francs-maçons supposés parmi les parlementaires: on constate alors que les francs-maçons constituent une minorité certes, mais représentent une force qui leur donne une visibilité réelle. En analysant systématiquement les comptes rendus des débats à la Chambre des députés pour la loi sur l'obligation et la laïcité, nous avons en effet pu suivre l'attitude de 79 députés francs-maçons qui représentent plus de $15 \%$ du total des députés et environ $22 \%$ des députés de gauche et du centre gauche. Notons qu'il ne semble pas exister de député franc-maçon de droite à la Chambre. Les sénateurs francs-maçons sont moins nombreux : ils sont 20 , soit environ $7 \% \mathrm{du}$ total des sénateurs et $13 \%$ des sénateurs de gauche et du centre gauche. Là encore, relevons qu'il ne semble pas exister de sénateur franc-maçon à droite.

L'analyse permet ensuite d'identifier la part effective prise par les francs-maçons supposés dans les débats. La méthode utilisée est simple: la lecture systématique du compte rendu des débats parlementaires dans le Journal officiel permet de relever toutes les interventions favorables au programme républicain pour la laïcité. Parmi ces intervenants se trouvent les francs-maçons que nous avons pu identifier comme tels, sans savoir s'ils sont tous francs-maçons actifs en 1879.

(1) P. Chevallier, op. cit.

(2) Même si Gambetta n'a pas été un franc-maçon actif, des délégations de 70 loges participèrent à ses obsèques le 6 janvier 1883 ( $c f$. J. Lalouette: «Francs-maçons et libres penseurs», art. cit., p. 73). 
Nous avons, malgré ces réserves, tenté de calculer la place occupée par les francs-maçons dans ces débats. Le résultat obtenu est sans ambiguïté. Il apparaît en effet très clairement que cette place est au total considérable: les francs-maçons supposés occupent en apparence plus de la moitié du temps de parole lors du débat sur l'obligation et la laïcité à la Chambre des députés, et un peu moins de la moitié au Sénat. Même si l'on prend en compte la marge d'erreurs inhérente à tout travail de ce genre, nous pensons pouvoir affirmer que la place prise par les parlementaires francs-maçons dans les débats à la Chambre ou au Sénat est sans commune mesure avec leur importance numérique dans les Assemblées.

Au-delà de cette manifestation concrète d'une apparente emprise maçonnique, la question est également mise en relief dans les débats parlementaires par les attaques antimaçonniques auxquelles se livrent les députés et les sénateurs de l'opposition. Nous avons relevé plusieurs de ces attaques à la Chambre des députés et au Sénat. Ces attaques antimaçonniques de la droite parlementaire semblent donner du crédit à la thèse d'une organisation très structurée de la francmaçonnerie pour faire aboutir le programme républicain en faveur de l'école primaire. Mais on ne peut évidemment pas se contenter de ces accusations proférées à la tribune. L'analyse détaillée de certaines interventions des parlementaires francs-maçons doit nous permettre de vérifier s'il y a, ou non, unité de vue et unité de vote des parlementaires francs-maçons, ce qui est un minimum si l'on veut parler de «plan» ou de «complot» maçonnique.

\section{L'attitude des parlementaires francs-maçons lors du débat sur la laïcité}

\section{Le débat à la Chambre des députés}

Vingt députés francs-maçons vont s'exprimer pendant les 9 jours de discussion de la loi, lors de la première lecture qui se déroule du 5 au 25 décembre 1880. Pendant toute l'intervention de Paul Bert, le 5 décembre 1880, cinq députés francs-maçons (et seulement deux autres députés républicains) interviennent (1) et apportent leur soutien au président de la commission pour la laïcisation des programmes, et pour contrer les députés de droite.

(1) $J O, 5$ décembre 1880. 
Le 14 décembre (1), les députés francs-maçons qui interviennent sont tous des députés d'extrême gauche, membres par ailleurs de l'Union démocratique de propagande anticléricale. On entend ainsi Barodet qui déclare, «vous avez vos églises et vos curés pour donner votre enseignement», et Casse qui s'oppose au député monarchiste Villers affirmant que «la morale sans Dieu sera socialiste» en lui répondant: «ce sont les congrégations qui veulent la propriété collective». Le 17 décembre, Lockroy et Barodet se livrent à une violente attaque anticléricale et antireligieuse. Lockroy est particulièrement en verve. Pour lui, l'urgence, c'est la question du personnel et il faut aller plus vite que le ministre pour éviter le retour des congrégations s'il y a un revirement politique (2). On ne doit pas faire confiance aux congrégations car «elles obéissent à un chef étranger». Les écoles congréganistes obtiennent de bons résultats car elles séparent les élèves pauvres des autres (3), elles soutiennent «les patois locaux et nuisent à la langue nationale libératrice, elles imposent des châtiments aux élèves » (4). Sur ce dernier point, le député de droite Keller attaquera à son tour «les instituteurs laïques qui donnent des coups» (5). Enfin, l'intervention de Lockroy se termine sur les congréganistes qui font vœu de chasteté mais qui sont «deux fois plus condamnés que les laïques» pour des affaires de mœurs.

Lors de la discussion des articles du projet de loi, et tout particulièrement lors de la discussion de l'article 1 qui fixe les matières à enseigner, on voit ainsi à l'œuvre les députés francs-maçons les plus intransigeants. Ces derniers sont très réactifs chaque fois qu'un amendement du centre gauche spiritualiste vise à trouver des voies de consensus. Ainsi, quand le 21 décembre de Lacretelle propose que le programme de l'école primaire comporte des «notions générales sur l'existence de Dieu, indépendants de tout dogme», il se fait sèchement contrer, de leur banc, par deux francs-maçons: Périn de Limoges qui déclare: «Nous ne sommes pas là pour discuter l'exis-

(1) $J O, 15$ décembre 1880.

(2) $J O, 18$ décembre 1880. Allusion aux prochaines élections de 1881. Cet argument a déjà été utilisé au moment du vote de l'article 7 . Les députés de droite jouent d'ailleurs de cet argument. Nombreuses sont, en effet, les prises de parole de leur part pour annoncer que la République ne durera pas.

(3) Argument déjà donné par Jules Ferry lui-même lors du débat sur la gratuité.

(4) C'est à ce moment qu'intervient Clemenceau pour confirmer qu'on frappe les élèves dans les écoles congréganistes.

(5) $J O, 21$ décembre 1880. 
tence ou la non-existence de Dieu», et Cantagrel, de la loge $L a$ Renaissance de Paris et membre de l'Union démocratique de propagande anticléricale qui ajoute: «Dieu est une hypothèse » (1).

Le même jour, Trarieux, un autre déiste du centre gauche, constatant que personne n'est monté à la tribune pour contredire de Lacretelle, propose une autre formule pour la rédaction des programmes: "Préparer les enfants à la pratique de toutes les vertus chrétiennes». Immédiatement, plusieurs francs-maçons interviennent. Allain-Targé, Périn: "Ce n'est pas la question en discussion, et voilà pourquoi, on ne vient pas à cette tribune », Madier de Montjau: «Nous n'avons pas à faire ici profession de religion ou d'irréligion», Casse: «Nous ne sommes pas à l'église», Lockroy: «nous ne sommes pas au confessionnal», etc. Pendant cette passe d'armes, Ferry reste silencieux et ne s'oppose pas aux spiritualistes. Il ne dit rien, et les députés francs-maçons non plus quand, sur les devoirs envers Dieu, Chevandier, le franc-maçon de Die, déclare de son banc à l'adresse de Trarieux et de Lacretelle: «c'est à mettre dans une circulaire» (2).

Sur la question de l'utilisation possible des locaux scolaires par le curé pour qu'il puisse y donner l'enseignement religieux en dehors des heures scolaires, c'est un député franc-maçon modéré et spiritualiste, par ailleurs classé au centre gauche (3), Lavergne, de Castres, qui produit un amendement qui prend manifestement ses frères députés à contre-pied: "Quand l'église et l'école sont distantes de plus d'un kilomètre, les curés sont autorisés à utiliser les locaux scolaires» (4). La question des locaux est délicate (5). Les francs-

(1) $J O, 22$ décembre 1880.

(2) Propos à relever car, comme on le sait, c'est ce qui se produira: le nom de Dieu ne sera pas mentionné dans le texte de la loi mais figurera dans la circulaire des programmes jusqu'en 1923.

(3) Jérôme Grévy, op. cit., p. 59.

(4) $J O, 22$ décembre 1880.

(5) Les locaux scolaires seront finalement interdits au catéchisme. Rambaud donne son opinion: "Au surplus, l'interdiction absolue des locaux scolaires à l'enseignement religieux était excessive. [...] Elle se comprenait à Paris et dans la plupart de villes, mais non dans les villages, dans les hameaux, où l'on n'a pas plusieurs espèces de locaux, ni dans les pays de neige, aux hivers rigoureux, où l'on arrivait à interdire en fait l'instruction religieuse aux enfants. Cette disposition fut arrachée à Jules Ferry par les plus avancés du parti, et parce qu'il fallait «aboutir». Dans la pratique, et jusqu'à ce jour, on a toujours admis des accommodements», Rambaud: Jules Ferry, Paris, Plon, 1903, p. 146. 
maçons en discutent en dehors du Parlement et ne sont pas tous d'accord. L'ancien instituteur Francolin s'exprime dans sa revue: on a tort, dit-il, «de laisser la faculté de donner l'enseignement religieux dans le local de l'école, et pendant les classes. Nous l'avons prédit, ce sera source de difficultés» (1). Le gouvernement et la commission ont accepté l'amendement de Lavergne mais ont porté la distance à deux kilomètres. C'est alors que Barodet intervient à la fois contre le député franc-maçon Lavergne et contre la Commission, où se trouvent également des francs-maçons, en déposant un amendement sur l'interdiction totale des locaux scolaires.

Selon Barodet, l'enseignement congréganiste ne «se recommande ni par l'intelligence, ni par la douceur, ni par le patriotisme (2), ni par l'honorabilité » (3). Barodet établit sa démonstration en trois temps. Il commence par critiquer le ministre et la commission qui donne, en fait, «plus d'importance et de solennité à l'enseignement religieux en introduisant le prêtre dans l'école (rires à gauche). On lui fait l'honneur d'un article spécial [...]. On fait de l'école une succursale de l'église $[\ldots]$. Le prêtre saura bien reprendre ce qui lui manque [...] Je dis que vous donnez à l'instituteur un maître [...]. Le prêtre s'installera dans l'école où les inspecteurs ne passeront qu'une fois, deux fois au plus par an». Le deuxième argument de Barodet est que si l'on confie l'enseignement religieux aux prêtres, ils « vont avoir du travail» et réclameront donc des vicaires. Votre loi, poursuit l'ancien séminariste (4), «vous conduira tout droit à une augmentation du personnel et du budget des cultes. (Très bien! Très bien! à gauche)».

Enfin, Barodet traite des locaux scolaires en eux-mêmes, dans une diatribe visiblement très préparée qui fait beaucoup d'effet sur l'assemblée. Puisque la salle de classe, dit-il, va servir à l'enseignement religieux, «le prêtre va y placer des emblèmes religieux (5). On

(1) L'École nouvelle, juin 1880, p. 40.

(2) Cette idée, nous l'avons montré, est dans l'air du temps chez les francsmaçons et chez les républicains en général: les Congrégations, en laissant le peuple dans l'ignorance, ont préparé la défaite. Patriotisme et anticléricalisme sont donc liés dans leur esprit. Voir notre thèse, op. cit.

(3) $J O, 24$ décembre 1880.

(4) J. Lalouette: La libre pensée en France, op. cit., p. 92.

(5) L'argument ne manque pas d'opportunité puisqu'au même moment le nouveau règlement des écoles de la Seine s'efforce justement de faire enlever ces emblèmes religieux. 
ne pourra s'y opposer car ce sont ses instruments de travail et de démonstration (protestations et rires ironiques à droite) [...]. Que devient l'enseignement laïque? [...]. L'école deviendra une petite chapelle! [...]. Au moment où l'on parle de la séparation de l'Église et de l'État, on appelle le prêtre qui profitera de l'hospitalité que vous voulez lui offrir pour attaquer, au nom du Pape et du Syllabus, les institutions civiles et républicaines du pays, et cela où ? Dans un édifice au frontispice duquel on lit: mairie, école primaire! [...]. Ayez le courage, une bonne fois pour toutes, de dire "chacun chez soi".

Barodet exige un scrutin public sur son amendement. Sa demande est signée par 23 députés, parmi lesquels nous avons pu identifier 9 francs-maçons. Son amendement est nettement rejeté par 277 voix contre 137. Mais l'amendement Barodet a été voté par 42 députés francs-maçons, soit les trois quarts des 56 députés francs-maçons qui ont participé au vote. Seuls 14 députés francs-maçons (dont Ferry luimême et Constans le nouveau ministre de l'Intérieur, alors que le précédent ministre de l'Intérieur franc-maçon, Lepère, vote avec Barodet) que l'on peut considérer comme modérés, et pour certains, de plus en plus isolés car spiritualistes, restent fidèles à la ligne gouvernementale. Parmi eux, le préfet de police Andrieux, Langlois, Lavergne, Méline.

Après le scrutin, Madier de Montjau et Laisant maintiennent la pression et disent fortement qu'ils voteront contre le texte présenté par le ministre et la commission. C'est d'ailleurs ce que 40 députés francs-maçons font, finalement, en votant contre l'amendement de Paul Bert qui propose l'utilisation des locaux scolaires le dimanche et les jours fériés. Seuls deux députés qui avaient voté l'amendement Barodet changent de camp et décident de rejoindre les modérés qui passent ainsi à 16 .

Ce sont les mêmes députés francs-maçons radicaux qui, avec les députés de la droite, refuseront de voter l'ensemble de l'article 2. A. Prost avait déjà indiqué que, lors du scrutin sur les locaux scolaires, «les radicaux, hostiles à toute venue du curé à l'école, avaient mêlé leurs voix à celles de la droite» (1). Nous pouvons ainsi ajouter que, par leur vote, les francs-maçons intransigeants, qui représentent à ce moment $60 \%$ du total des députés francs-maçons, font pencher le scrutin en défaveur du gouvernement: l'article 2 est en effet refusé

(1) A. Prost, op. cit., p. 200. 
par 227 voix contre 200. Une analyse du vote permet de retrouver la même quinzaine de députés francs-maçons modérés, fidèles au ministre.

Cette attitude pour le moins disparate et hostile au gouvernement des députés francs-maçons radicaux ne modifie pas la position des députés de la droite. Pour eux, il ne fait pas de doute que les députés qui s'expriment le font au nom des loges et du Grand Orient de France qu'ils représentent à la Chambre. Le 17 décembre par exemple, quand Lockroy conclut son intervention en disant qu'il faut «empêcher d'enseigner les Frères de la Doctrine chrétienne», de la Bassetière lui répond «pour les remplacer par des francs-maçons!» (1). Après l'intervention de Villers qui se prononce pour «l'union de l'instituteur et du prêtre » et qui soutient «les populations qui protestent contre les entreprises tyranniques ourdies au ministère de l'Instruction publique», le député de la Bassetière ajoute «et dans les loges!» (2). C'est aussi ce que pense Keller: il y a un plan maçonnique pour détruire les croyances religieuses et il le décrit longuement à la tribune, le 20 décembre 1880, en réutilisant d'ailleurs un argument qui a déjà servi contre Jules Ferry: «Je l'ai déjà dit à cette tribune et je ne crains pas de le répéter, il y a un plan organisé pour détruire les croyances religieuses dans l'esprit des enfants, c'est un plan maçonnique (exclamations et rires à gauche)» $(3)$.

\section{Les débats au Sénat}

Les sénateurs francs-maçons prennent également une part active dans le débat. Victor Schœlcher, vieux républicain qui préside, depuis sa fondation en mai 1880, l'Union démocratique de propagande anticléricale (4), est le président de la commission chargée d'étudier le projet. Il intervient donc pratiquement chaque jour. Classé à l'extrême gauche au début de la Troisième République (5), il est considéré comme un franc-maçon ayant peu fréquenté les loges depuis 1848. Avec Schœlcher, ce sont deux anciens de 1848, les francsmaçons Tolain et Testelin, qui monopolisent l'essentiel de la parole maçonnique lors du débat, laissant ainsi peu d'espace aux autres francs-maçons qui interviennent plus ponctuellement: Hérold, Le

(1) $J O, 18$ décembre 1880.

(2) $J O, 15$ décembre 1880.

(3) $J O, 21$ décembre 1880.

(4) J. Grévy, op. cit., p. 142.

(5) J. Lalouette, op. cit., p. 512. 
Royer, Oudet et Pelletan. Les prises de parole de Jules Simon ne peuvent plus être comptabilisées comme celles d'un franc-maçon puisqu'on sait qu'il a rompu avec la franc-maçonnerie en 1880, à partir du moment où les spiritualistes y deviennent minoritaires. La plupart du temps, il s'agit de courtes interventions destinées à encourager le ministre ou à contrer l'opposition.

Les sénateurs francs-maçons font également un certain nombre de déclarations violemment antireligieuses. Tolain (1) est particulièrement en verve. Le 4 juin 1881, par exemple, sa longue intervention est anticatholique et anticongréganiste, comme le montre ce court extrait où l'on voit le sens de la provocation de ce sénateur: «La liberté que vous venez de défendre, c'est une liberté d'une nature particulière, spéciale, c'est la liberté des catholiques» Puis, Tolain ajoute, citant un propos de Thiers en 1849, «Je demande formellement autre chose que ces instituteurs laïques dont un grand nombre est détestable. Je veux des frères (2) (exclamations et rires à gauche.) Un sénateur à droite: Nous aussi! M. Tolain: Progrès et catholicisme sont deux choses absolument contradictoires » (3).

Cette déclaration enflammée n'est pas de nature à aider Jules Ferry dont l'attitude et le ton, lors de ce débat, visent au contraire à rassurer les sénateurs du centre en essayant de les persuader que sa loi n'est pas sectaire. Il doit donc répondre à Tolain pour s'en désolidariser. C'est ce qu'il fait à la séance suivante. Après avoir affirmé que la morale qu'il appelle de ses vœux «est la bonne vieille morale de nos pères, la nôtre, la vôtre, car nous n'en avons qu'une...», il prend nettement ses distances avec certains de ses frères francsmaçons du Sénat, dont Tolain, «qui a produit à cette tribune une attaque violente contre le catholicisme [...] Est-ce que jamais [...] on m'a entendu proférer une parole d'outrage contre la foi d'un citoyen français? [...] J'ai toujours pensé que l'œuvre du gouvernement n'est point une œuvre de sectaires; que nous n'avons ni le devoir ni le droit de faire la chasse aux consciences (Très bien! Très bien! à gauche et

(1) La droite reproche à Jules Ferry d'avoir confié à Tolain la présidence d'une commission chargée de préparer un projet de loi sur l'enseignement primaire supérieur: «le projet de loi sur l'enseignement obligatoire et laïque a beau porter le nom de M. Jules Ferry, on l'appellera le projet Tolain.», JO, 5 juin 1881.

(2) En italique dans le texte du compte rendu.

(3) $J O, 5$ juin 1881. 
au centr.) [...] Oui, nous sommes entrés résolument dans la lutte anticléricale $[\ldots]$ Oui nous avons voulu la lutte anticléricale, mais la lutte antireligieuse... Jamais! Jamais! (très bien! et applaudissements à gauche» (1).

Cette dernière formule utilisée par Jules Ferry est largement connue. Mais ce qui a été moins mis en relief jusqu'à présent, nous semble-t-il, c'est le contexte dans lequel le ministre éprouve le besoin de faire cette mise au point, à savoir la pression exercée par les intransigeants de l'extrême gauche au premier rang desquels on trouve des francs-maçons. Jules Ferry est, une fois de plus, gêné par ses propres «frères». Les sénateurs de droite ne s'y trompent pas qui en tireront argument dans plusieurs attaques antimaçonniques.

C'est tout d'abord Chesnelong qui soupçonne les républicains de vouloir remplacer la croix du Christ par le triangle maçonnique: «Vous aspirez à étendre et à développer l'instruction: vous avez raison et c'est un noble souci; mais pour cela, il n'y a pas deux méthodes, il n'y en a qu'une: c'est d'abord d'inspirer confiance aux familles et de répondre à leurs sentiments; c'est ensuite de faire de bons maîtres qui aient le sentiment de leur mission, qui s'y renferment, qui ne deviennent pas, selon l'expression de M. Thiers, des «anticurés », et qui ne soient pas chargés de préparer un avenir où la croix du Christ sera remplacée par le triangle maçonnique» (2). Le thème du triangle maçonnique est repris le lendemain par le sénateur Jouin qui fait de ce symbole un ennemi de la liberté: «J'ai écouté avec une religieuse attention tout ce qui a été dit par nos collègues sur ces graves questions de la gratuité, de la laïcité, de l'obligation. Pour moi, c'est un triangle de fer dans lequel la liberté est étouffée (applaudissements à droite). Non, il n'y a pas de liberté possible sous cette formule triangulaire» (3). La mise en évidence de l'attitude des élus francs-maçons lors des délibérations législatives montre donc, de façon très nette, qu'il n'y a pas d'unanimité chez les francs-maçons et même qu'un nombre important d'entre eux n'hésite pas à gêner l'action de leur «frère» Jules Ferry.

Quand ils parlent et votent de cette manière, quand ils se divisent à ce point, les parlementaires francs-maçons ne se comportent donc

(1) $J O, 11$ juin 1881.

(2) $J O, 4$ juin 1881.

(3) $J O, 5$ juin 1881. 
pas comme ils le feraient s'ils étaient des francs-maçons chargés d'appliquer une consigne venue de leur Ordre. Il n'existe pas, contrairement à ce que disent les parlementaires de l'opposition, de «plan» maçonnique, préparé dans les loges et mis en œuvre à la Chambre et au Sénat, pas plus qu'il n'existe de tactique pour manœuvrer de façon homogène dans les débats et dans l'action. En outre, les propos intransigeants des Lockroy, Barodet, Madier de Montjau, Tolain et des autres sont probablement ceux que l'on pouvait sans doute entendre dans les réunions de l'Union démocratique de propagande anticléricale, dans les associations de libre pensée ou dans certains cercles républicains, comme dans les réunions de certaines loges. En tout état de cause, ils ne résultent pas, nous venons de le montrer, d'une action organisée par le Grand Orient de France qui ne contrôle pas, à l'évidence, les députés et les sénateurs initiés.

Les prises de position de ces francs-maçons témoignent en fait, et peut-être surtout, du poids grandissant des libres penseurs et de l'extrême gauche dans la franc-maçonnerie, ce qui gêne certes le ministre par son intransigeance, mais qui peut aussi l'aider en le faisant apparaître modéré (1).

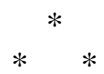

En fait, c'est essentiellement la question de la mise en œuvre effective de la laïcité qui fait problème chez les francs-maçons comme chez les républicains. Sur ce point, la diversité est telle entre les francs-maçons qu'il faut se garder de toute généralisation. Cela, après tout, ne peut surprendre quand on se souvient qu'une forte minorité des délégués des loges a souhaité, en 1877, le maintien de la référence au Grand Architecte de l'Univers dans les statuts du Grand Orient, et que le débat fait rage dans les loges sur la question des fondements de la morale dans l'école laïque. Pour toutes ces raisons, on ne peut donc trouver de traces d'un «plan organisé»par les

(1) Dans un discours prononcé à Épinal le 19 juin 1881, Jules Ferry, qui a sans doute en mémoire le vote de l'extrême gauche - dont des francs-maçons - avec la droite sur la question des locaux scolaires, situe de cette façon l'enjeu des élections législatives de 1881 : «Mettre définitivement à l'abri des coalitions de droite et d'extrême gauche, le Ministère voulu par la majorité ». Après des succès partiels de l'extrême gauche en 1883, il dira: «Le péril monarchique n'existe plus, mais un autre lui succède et il faut le regarder en face». Cité par Marcel Gauchet: «La droite et la gauche», in Pierre Nora (dir.): Les Lieux de mémoire. III. Les France. 1. Conflits et partages, p. 2549. 
francs-maçons pour la mise en œuvre du programme républicain pour l'instruction publique, au sens où l'exprime le député Keller en décembre 1880 , et où l'entendent habituellement les adversaires de la franc-maçonnerie.

André Encrevé avait déjà tiré les mêmes conclusions à propos d'un supposé complot protestant aux premiers temps de la Troisième République. Pour les cléricaux et pour les conservateurs, montre-t-il, «scandalisés par cette évolution qui les marginalise, une seule réponse est concevable, celle du complot. Complot «judéo-protestant» pour reprendre une expression de l'époque, auquel les francsmaçons prêteraient la main. Cette thèse du complot - paresseuse au fond car elle permet d'éviter de réfléchir sur ses propres erreurs - fait bon marché de la véracité historique» (1). Ce point de vue est confirmé par Patrick Cabanel qui montre combien «serait fallacieuse l'idée d'un pouvoir protestant capable de parler d'une même voix et de parler dans un seul sens » (2).

La solidarité maçonnique bute en permanence sur la question des modalités de mise en œuvre de la laïcité, et appartenir à la même loge et à la même Obédience maçonnique ne suffit pas à gommer des clivages aussi fondamentaux. Au Parlement, on n'est pas d'abord un député ou un sénateur franc-maçon, on est antireligieux ou spiritualiste, on est radical ou opportuniste; on est à l'extrême gauche (Madier de Montjau, Tolain), à l'Union républicaine (Gambetta et ses amis), à la Gauche républicaine (Jules Ferry et ses amis), ou au Centre gauche (Jules Simon). Les parlementaires francs-maçons sont bien en peine de fomenter quelque complot que ce soit car ils sont représentatifs, en réduction, des nuances républicaines et de leur évolution, nuances qui apparaissent, au bout du compte, plus fortes que l'appartenance maçonnique.

L'accusation de manipulation occulte du gouvernement de la république par les loges maçonniques pour chasser Dieu de l'école primaire n'est donc pas fondée. L'Église catholique et les parlementaires de droite avaient besoin d'un bouc émissaire pour trouver une justification à leurs propres difficultés et à leur perte d'influence dans la société, comme l'a démontré le dénombrement systématique des

(1) André Encrevé: Les Protestants en France de 1800 à nos jours, Paris, Stock, 1985, p. 203.

(2) Patrick Cabanel: Le Dieu de la République: aux sources protestantes de la laïcité, 1860-1900, Rennes, Presses universitaires de Rennes, 2003, p. 108. 
nombreuses attaques antimaçonniques portées par les parlementaires de droite.

Il apparaît que les francs-maçons, moins prudents dans l'extériorisation de leurs actions après 1878 , se sont bien gardés de démentir énergiquement leurs détracteurs, trop heureux qu'ils étaient sans doute de l'importance qu'on voulait bien leur donner. À cet égard, il nous semble que les francs-maçons de Toulouse expriment bien, en 1883, le sentiment dominant, tant chez les francs-maçons que chez leurs adversaires quand ils disent que «les ennemis de la démocratie, les contre-révolutionnaires et les cléricaux ne se font pas d'illusions: ils ne redoutent pas les virtuoses de la dynamite, mais ils ont une peur atroce du Franc-Maçon» (1).

D'une certaine façon d'ailleurs, il existe une accusation symétrique de complot qui touche à la fois les francs-maçons et les «ennemis de la démocratie» que sont les jésuites. De même que les francs-maçons les plus virulents avaient besoin de mettre en avant un supposé complot des jésuites pour justifier les lois laïques, les catholiques avaient besoin d'expliquer leur échec par l'existence d'un complot maçonnique. Ce fut complot contre complot, les débats parlementaires fourmillent de citations qui le montrent à l'envi. Les deux camps ont certainement fini par y croire. Comme l'indique A. Prost, «Laïques et cléricaux forment un couple de partenaires indissociables qui se constituent et se renforcent réciproquement» (2). Pierre Miquel (3) a également montré qu'au début de la Troisième République, chaque camp en est venu à supposer que le pouvoir véritable ne pouvait appartenir aux parlementaires. Et si le pouvoir n'est pas au Parlement, c'est qu'il est «ailleurs». De 1871 à 1878 , les républicains «le croient à Rome ou dans des «jésuitières», pouvoir occulte (4) tendant à écarter les républicains au profit des notables» (5). Ainsi, au pouvoir souterrain des jésuites, s'oppose celui que l'on attribue aux francs-maçons.

(1) La Chaîne d'union, janvier 1883, p. 15.

(2) A. Prost, op. cit., p. 177.

(3) Pierre Miquel: La Troisième République, Paris, Fayard, 1989. Voir aussi les analyses de Jean-Marie Mayeur: Les débuts de la III République, Paris, Seuil, 1973 et de Maurice Aguhlon: «Républicains sous le Second Empire», in Jean Tulard (dir.): Dictionnaire du Second Empire, Paris, Fayard, 1995.

(4) Jules Ferry ne déclare-t-il pas le 16 juin 1877: «Le rideau est tombé, et le gouvernement occulte devient le gouvernement officiel»(Pierre Miquel, op. cit., p. 237).

(5) Ibid., p. 15. 
Peut-être est-ce Francolin qui résume le mieux comment le mythe maçonnique a pu être entretenu par les francs-maçons eux-mêmes, quand il rappelle, au Convent de 1879, l'action de la franc-maçonnerie pour la création d'écoles. Il s'adresse ainsi aux délégués des loges: "Votre trop grande modestie vous a souvent empêchés de dire tout le bien que vous avez fait; vous l'ignorez vous-même, vous ignorez que vous êtes les instigateurs de presque toutes les heureuses initiatives modernes...»(1). Il est permis de penser que les Vénérables qui assistent au Convent ne sont pas complètement dupes. Car ce que dit Francolin relève d'un raisonnement très spécieux: si les francs-maçons eux-mêmes (et au Convent il s'agit des francsmaçons les mieux informés puisque l'on a affaire à des Vénérables) n'ont pas la connaissance de tout ce qu'ils font, alors toutes les supputations sur le pouvoir occulte maçonnique devient possible, et leurs adversaires peuvent craindre, ou feindre de craindre, le pire. Certains contemporains l'avaient compris. Nous pensons en particulier à l'ancien préfet de police Louis Andrieux quand il déclare en 1885, année de son exclusion de la franc-maçonnerie: «Laissons les braves gens des deux partis croire, suivant l'inclination de leurs esprits, que les francs-maçons et les jésuites commettent des atrocités » (2).

Dans le même temps, on peut aussi considérer que, puisque diversités républicaine et maçonnique il y a, les loges ont tout de même permis à ces différentes tendances républicaines et libres penseuses de se côtoyer et de débattre, parfois, on l'a vu, en amont des débats parlementaires. Même si d'autres cercles ou associations ont pu jouer un rôle de nature identique, il n'en reste pas moins que cette fonction remplie par les loges a sans doute été essentielle dans les premiers temps de la mise en place de notre instruction publique.

Connaissant elle-même, tout au long de cette période, une mutation qui démocratise et laïcise son fonctionnement, la franc-maçonnerie accompagne davantage les évolutions qu'elle ne peut les provoquer en raison de sa trop grande hétérogénéité. Au bout du compte, la franc-maçonnerie n'a-t-elle pas été davantage utilisée qu'elle n'a été l'instigatrice d'un mouvement, auquel elle a certes pris une grande part, mais qui lui a assez largement échappé ? Poser cette

(1) $B D G O D F, 1879$, p. 334.

(2) Louis Andrieux : Souvenirs d'un préfet de police, réédition, Paris, Mémoire du livre, 2002, p. 120. 
question, au terme de cette étude, n'est sans doute pas de nature à diminuer le rôle de la franc-maçonnerie dans la construction de notre école républicaine. Les loges maçonniques ont incontestablement aidé à penser l'école de la République, et il est inutile d'entretenir le mythe d'une franc-maçonnerie toute puissante et comploteuse pour valoriser un rôle de toute façon essentiel.

Jean-Paul DELAHAYE Professeur associé à l'Université Paris 5 